\title{
Does parochial cooperation exist in childhood and adolescence? A meta-analysis
}

\author{
Aleksandra Lazić ${ }^{1,2}$, Danka Purić ${ }^{1,2}$, and Ksenija Krstić ${ }^{1,3}$ \\ ${ }^{1}$ Department of Psychology, Faculty of Philosophy, University of Belgrade \\ ${ }^{2}$ Laboratory for Research of Individual Differences, Faculty of Philosophy, University of Belgrade \\ ${ }^{3}$ Laboratory of Developmental Psychology, Faculty of Philosophy, University of Belgrade
}

\section{- Postprint -}

This is the peer reviewed version of the following article: Lazić, A., Purić, D., \& Krstić, K. (2021). Does parochial cooperation exist in childhood and adolescence? A meta-analysis. International Journal of Psychology, 56(6), 917-933., which has been published in final form at https://doi.org/10.1002/ijop.12791. This article may be used for non-commercial purposes in accordance with Wiley Terms and Conditions for Use of Self-Archived Versions. This article may not be enhanced, enriched or otherwise transformed into a derivative work, without express permission from Wiley or by statutory rights under applicable legislation. Copyright notices must not be removed, obscured or modified. The article must be linked to Wiley's version of record on Wiley Online Library and any embedding, framing or otherwise making available the article or pages thereof by third parties from platforms, services and websites other than Wiley Online Library must be prohibited.

\section{Author Note}

Aleksandra Lazić, (Dhttps://orcid.org/0000-0002-0433-0483

Danka Purić, (Dhttps://orcid.org/0000-0001-5126-3781

Ksenija Krstić, (Dhttps://orcid.org/0000-0002-3604-270X

Corresponding author: Aleksandra Lazić, aleksandra.lazic@f.bg.ac.rs, lazic.ale@gmail.com.

Author contributions: Conceptualization: $\mathrm{AL}$ and KK. Data Curation: AL and DP. Formal Analysis: AL and DP. Investigation: AL. Methodology: AL, DP, and KK. Project Administration: AL. Validation: AL and DP. Visualization: DP. Writing - Original Draft Preparation: AL and DP. Writing - Review \& Editing: AL, DP, and KK.

Acknowledgements: We would like to thank the authors who provided us with additional information and data so that we could include their research in this meta-analysis.

Data accessibility: The dataset and the codebook are available at https://osf.io/4e9pm.

Conflict of interest: The authors declare they have no conflict of interest.

Funding: This work was supported, in part, by the Ministry of Education, Science and Technological Development of the Republic of Serbia Project No. 179018. 


\begin{abstract}
Although previous meta-analytic evidence supports the existence of parochialism in cooperation among adults, the extent to which children and adolescents are more willing to incur a personal cost to benefit ingroups, compared to outgroups, is not yet clear. We provide the first meta-analysis on the existence and magnitude of parochialism in cooperation among pre-adults. Based on 20 experimental economics studies $(k=69, N=$ 5268, age = 3-19, 12 countries, published 2008-2019), a multilevel meta-analytic model revealed a small overall effect size indicating that children and adolescents were more cooperative towards ingroups $(d=0.22,95 \% \mathrm{Cl}[.07, .38])$. A series of single-moderator analyses tested for the following conditions: participant age and sex; game type ([mini]dictator game, prisoner's dilemma, public goods dilemma, trust game, ultimatum game); outcome interdependence; membership manipulation (between- vs. within-subjects); group type (natural vs. experimental); reward type (monetary vs. non-monetary); and country of the participant. Parochial cooperation did not vary with participants' age. Parochialism was larger in non-interdependent (dictator-type) compared to interdependent (bargaining and social dilemma) games. There were no moderating effects of group type, membership manipulation or reward type. To provide more data on how parochialism develops, primary studies should report age ranges more precisely and use more restricted age groups.
\end{abstract}

Keywords: parochial cooperation, intergroup bias, behavioural economics, children, meta-analysis 


\section{Does Parochial Cooperation Exist in Childhood and Adolescence? A Meta-Analysis}

Groups are a pervasive and persistent feature of our social lives. Whether it is by nation, religion, race, political party or language, everyone belongs to at least one group. What is more, throughout our life, we interact with people both within and outside our own group. What arises from this complex context is a seemingly pervasive tendency to favour the groups to which we belong (the ingroups) over the groups to which we do not (the outgroups), including their respective members (Hewstone et al., 2002). Discriminating between ingroups and outgroups has mixed economic implications. While it can strengthen the ingroup by increasing cooperation levels (e.g., the number of shared resources) among its members, it can harm the outgroup by decreasing cooperation levels with its members. Parochialism can thus potentially fuel tensions, competition, and hostility between groups (Bornstein, 2003; Choi \& Bowles, 2007; Fiske, 2002; Halevy et al., 2010).

Among the adult population, parochial cooperation ${ }^{1}$ has been extensively studied in many different societies, based on a multitude of attributes such as national identity, race, ethnicity, religion, and political party (for meta-analyses, see Balliet, Wu et al., 2014; Lane, 2016). Meta-analysing four decades of such studies, Balliet, Wu, and De Dreu (2014) found that people show a robust, although a consistently small, preference to incur a personal cost to benefit members of their ingroup, rather than members of their outgroup ( $d=0.32)$. This effect holds even for artificial group memberships that do not exist outside of the experimental situation (e.g., membership based on the preference for different types of abstract art or random assignment of numbers). Parochial cooperation among adults seems to be ubiquitous across the world; the above mentioned meta-analysis found no effect of the country where the study was conducted (Balliet, Wu et al., 2014), while two large-scale studies have recently shown that there is only a small amount of cross-societal variation in parochialism in the prisoner's dilemma game and trust game (Romano et al., 2017, 2021).

Is children's and adolescents' decision-making similarly shaped by parochialism when making others better off comes at a cost to themselves? The main aim of our metaanalysis was to answer this question. In a recent literature survey, Sutter et al. (2019) 
conclude that, with increasing age, children more often favour members of their own group and that children's and adolescents' parochialism in economic behaviour typically shows patterns similar to adults'. Over (2018) likewise concludes that children - as young as 3 and up to about 12 years - are, at least at times, more prosocial towards members of their own groups (i.e., more willing to help and share with them and comfort them in distress).

In the past fifteen years, experimental economics has seen an upsurge in interest in children's and adolescents' social preferences. Such research is important for at least three reasons. First, it can find developmental trends and reveal whether behavioural patterns identified in studies with adults apply to children and adolescents (Sutter et al., 2019). Second, consistently using the approach of experimental economic games - such as the dictator game or the prisoner's dilemma - across different age groups, can make age comparisons more meaningful (Gummerum et al., 2008). Third, knowing when parochialism develops, how, and why, can support policy interventions that try to promote positive intergroup relations among youth, for example, by identifying the points at which discrimination is not yet deeply entrenched and can be most easily modified (Killen \& Verkuyten, 2017). It has been argued that developmental research of intergroup behaviour would have even more potential to contribute to this applied area if it assumed a broader international perspective that focuses on the heterogeneity within and between cultures (Killen \& Verkuyten, 2017).

Here, we integrated studies conducted in the field of experimental economics that have explored parochialism in cooperation among children and adolescents. To our knowledge, this meta-analysis is the first to estimate the size of the effect that group membership has on cooperative decision-making among pre-adults. 


\section{Commonly Used Economic Games to Explore Intergroup Cooperation in Children and} Adolescents

Several economic games have been commonly used to study intergroup cooperative behaviour of children and adolescents (Table 1). These games sometimes differ from the games used in research with adults. For example, the choices are often simplified to ease the comprehension of their payoff implications.

In the (mini-)dictator game, there is no strategic interaction between the two players - the (mini-)dictator has complete power over the outcome of the game. The ultimatum game and the trust game involve some kind of bargaining - the cooperative behaviour of the first mover is likely to be motivated by expectations about how the second mover will respond (whether they will accept the offer in the ultimatum game and return some of the investment in the trust game). Social dilemma games, such as the prisoner's and the public goods dilemma, are characterized by a tension between the mutually efficient outcome (e.g., both players cooperate by giving all of their resources to the other player) and selfish defection (e.g., the player keeps all of the endowment for oneself). 


\section{Table 1}

Commonly Used Economic Games to Study Intergroup Cooperation Among Children and Adolescents

\begin{tabular}{ll}
\hline Name & Brief description \\
\hline Dictator Game & $\begin{array}{l}\text { Player A (the dictator) decides how much of the endowment (if any) to give } \\
\text { to Player B (the recipient), who must accept the allocation. }\end{array}$ \\
$\begin{array}{l}\text { Mini-Dictator Game or } \\
\text { Sharing Game }\end{array}$ & $\begin{array}{l}\text { Player A (the mini-dictator) is offered two predetermined ways to split the } \\
\text { resources with Player B (the recipient). Player A chooses either an } \\
\text { egalitarian (e.g., } 1 \text { to A, 1 to B) or a selfish (e.g., 2 to A, O to B) allocation. } \\
\text { Player B must accept the allocation. }\end{array}$ \\
Ultimatum Game & $\begin{array}{l}\text { Player A (the proposer) is offered an endowment and decides how to divide } \\
\text { it with Player B (the responder), who can accept or reject Player A's offer. }\end{array}$ \\
$\begin{array}{l}\text { If Player B accepts the offer, both players receive the proposed division; if } \\
\text { Prust Game }\end{array}$ & $\begin{array}{l}\text { Player B rejects it, both players are left with nothing. } \\
\text { Player A (the investor) receives an endowment and decides how much (if } \\
\text { any) to transfer to Player B (the trustee). The experimenter then multiplies } \\
\text { this investment by some amount. Upon receiving the investment, Player B } \\
\text { decides how much (if any) to send back to Player A. }\end{array}$ \\
Modified Prisoner's & $\begin{array}{l}\text { Players A and B both start with the same endowment. They simultaneously } \\
\text { (in some versions - sequentially) decide how much (if any) of their } \\
\text { endowment to give to the other player. The experimenter then multiplies } \\
\text { the resources they give away by some amount. }\end{array}$ \\
\hline
\end{tabular}

Note. In the Ultimatum Game, Player A is the focal player in our analysis.

\section{Overview of the Present Meta-Analysis}

In this meta-analysis, we collected and integrated findings from experimental economics studies on parochialism in costly cooperation among children and adolescents. Our main aim was to determine to what extent children and adolescents show evidence of parochialism in cooperation. Moreover, we were interested in assessing several moderator variables that may reveal boundary conditions of this tendency.

Specifically, regarding age, we focused on two questions, (1a) At what age do children first show evidence of parochialism in cooperation? and (1b) How does parochialism in cooperation change with age?

We wanted to examine the role of (2) the economic game that was used since, as explained above, the games differ in the type of social preferences and beliefs they elicit (e.g., Everett et al., 2015), as well as (3) the outcome interdependence of those games. 
Whereas the outcome in the (mini-)dictator game depends only on the choices of the (mini)dictator, the outcomes in bargaining games and social dilemmas depend on the choices of both players. According to the approaches that emphasize (bounded) generalized reciprocity, people should be more cooperative towards those on whom they are dependent and this effect should be stronger for the ingroup because of the generalized expectation that one's ingroup members will cooperate (e.g., Gaertner \& Insko, 2000; Stroebe et al., 2005; Yamagishi et al., 1999; Yamagishi \& Kiyonari, 2000). The meta-analysis of intergroup cooperation among adults strongly corroborated this hypothesis (Balliet, Wu et al., 2014). However, it is unclear whether this tendency is present in children and adolescents as well.

Since assigning participants to interact with both an ingroup and an outgroup (on separate occasions) could amplify the effect of parochialism, we also explored the role of (4) within-subjects versus between-subjects design (where, in contrast, participants are randomly assigned to interact with either an ingroup or an outgroup).

Because participants might be more willing to cooperate with natural and salient groups with whom they have previously interacted and with whom they identify (Tajfel \& Turner, 1979), we tested the role of (5) naturally-occurring versus experimentally created group membership. Although experimental economists, as a rule, prefer to use money, it is impossible to do so when working with very young children. Therefore, we explored the role of (6) monetary versus non-monetary rewards, such as sweets or stickers. We also tested for possible (7) sex differences in parochialism. The male-warrior hypothesis predicts that boys would be more parochial because male cooperation has been shaped by the evolutionary history of violent intergroup conflicts, which promoted coalitional (us versus them) psychology (McDonald et al., 2012; Van Vugt et al., 2007). Lastly, as an exploratory analysis, we looked into the variation in parochial cooperation across (8) the countries of the participants.

We registered several additional study characteristics (listed below) to describe the data by illustrating the design and procedural details of the experiments included in the meta-analysis. 


\section{Method}

Our reporting strategy follows the PRISMA guidelines (Moher et al., 2009). The PRISMA checklist is available in the Supplemental Material (SM1, https://osf.io/6xu9q).

\section{Search Strategy}

We systematically searched the following databases from their earliest record to November 2017: ScienceDirect, EBSCOhost Web (which included Academic Search Premier, ERIC, MEDLINE, American Doctoral Dissertations, Business Source Premier), PsycARTICLES, EconPapers, PubPsych, Wiley Library, SAGE Journals, JSTOR, EconStor, Directory of Open Access Journals (DOAJ). We searched for grey literature in Open Access Theses and Dissertations (OATD), The DART-Europe E-Theses Portal, and OpenGrey.

We ran an updated search in February 2020 in Web of Science, Academic Search Premier, PsycARTICLES, EconPapers, PubPsych, Wiley Library, SAGE Journals, JSTOR, EconStor, DOAJ, OATD, DART-Europe, and IDEAS/RePEc, restricting the search to records from November 2017 to December 2019. We ran an additional search in February 2021 using OSF Preprints and the Cooperation Databank (Spadaro et al., 2020), for records published until December 2019.

We searched by title, abstract, and keywords for the following search string: (Population-Term-1 OR Population-Term-2 OR ... OR Population-Term-n) AND (Bias-Term1 OR Bias-Term-2 OR ... OR Bias-Term-n) AND (Game-Term-1 OR Game-Term-2 OR ... OR Game-Term-n). Population terms included “child", "toddler”, "kindergarten”, "adolescent”,... Bias terms included "intergroup bias", "intergroup discrimination”, "ingroup/outgroup favouritism/derogation", "parochialism",... Game terms included "cooperation", "altruism", "dictator game", "social dilemma",... The strategy was developed in ScienceDirect, prior to adaptation for the other databases. We also manually searched the reference lists of articles that were found to meet our inclusion criteria.

The complete search strategy is available in the Supplemental Material (SM2, https://osf.io/6xu9q). All searches were run with no country or language restrictions. 


\section{Eligibility Criteria}

To be included in the meta-analysis, studies had to meet the following main criteria.

1. Studies had to report empirical results from samples of children or adolescents. Studies were considered to include children when the average age of the sample was $<12$ years, and to include adolescents when the average age was $<19$ years and participants did not attend college yet.

2. Studies had to apply a commonly used economic game to measure and compare personally costly acts of cooperation with ingroup and outgroup members. These games had to involve participants allocating positive resources (rewards) between themselves and an ingroup or an outgroup member. The outgroup member had to be classified into a distinct group (which means they could not, for example, be introduced as an unclassified stranger $)^{2}$.

We excluded studies that fulfilled both inclusion criteria, but which measured cooperation only after an intervention aimed at enhancing cooperation or reducing parochialism, without a control group (e.g., Guerra et al., 2010). Since we are primarily interested in exploring the phenomenon of intergroup discrimination in cooperation among children and adolescents without it being directly influenced by any kind of external intervention, adding such studies would have introduced unnecessary heterogeneity in the sample of effect sizes. This also excluded one study where the cooperation partner was a victim of a transgression (McLoughlin \& Over, 2018). We excluded studies that used the socalled Tajfel Minimal Group Paradigm Matrices, as well as any other similar matrices specifically designed to measure intergroup competition rather than cooperation (e.g., Petersen et al., 2004; Stephan \& Kennedy, 1975; Tajfel et al., 1971). The other main reason for excluding the matrices is that they always involve participants allocating resources between an ingroup and an outgroup member, usually at no cost to themselves. Also not included were studies employing the "prosocial game" and the "envy game", where choosing to cooperate does not require participants to incur a personal cost (e.g., Fehr et al., 2008). For example, in the prosocial game, by choosing $(1,1)$ - that is, 1 for themselves and 1 for 
the partner - participants can, at no cost to themselves, deliver a benefit to the partner and avoid advantageous inequality $(1,0)$. In the envy game, participants can, again, deliver a benefit to the partner at no cost, but choosing $(1,2)$ over $(1,1)$ leads to a disadvantageous inequality. Finally, we excluded studies that investigated helping and comforting (e.g., Abrams et al., 2015; Bigler et al., 1997; Sierksma, 2018; Van Lange et al., 2018).

\section{Study Identification}

The original search (Figure 1) identified 10,745 records, 2,180 of which were removed as duplicates using reference management software. The remaining records were screened by examining the title and abstract in line with the eligibility criteria. Having removed the articles we judged as irrelevant or unrelated to our topic, we electronically retrieved 147 articles for full-text examination. If an article had multiple reasons for exclusion, we chose the primary reason in the order in which they are listed in Figure 1 . The original search yielded a total of fourteen articles, and another four were identified in the updated search. A separate study flow diagram for the original and the updated search is available in the Supplemental Material (SM3, https://osf.io/6xu9q). The studies were identified by the first author. 


\section{Figure 1}

Flow Diagram of the Identification of Literature for Inclusion in This Meta-Analysis

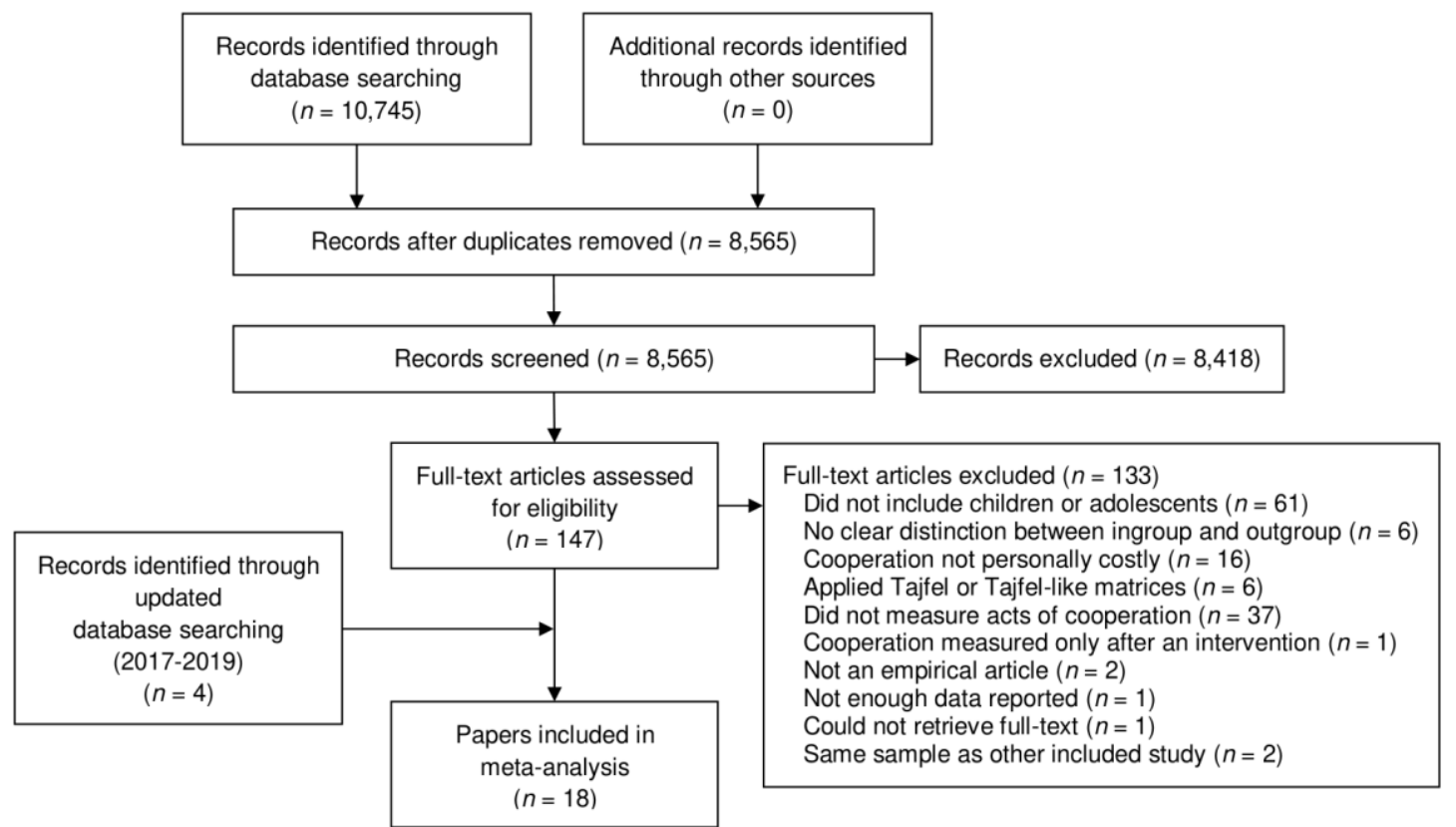

\section{Dataset}

Our final dataset consisted of 18 articles that contained 20 eligible studies reporting 69 effect sizes. All studies were published in peer-reviewed journals between 2008 and 2019. The studies included 53 independent samples and a total of 5,268 participants, approximately $50 \%$ of whom were male. There were 961 children below the age of six years; 2,886 children aged between six and twelve years; and 1,421 adolescents aged between twelve and nineteen years. The age of participants ranged from 3 to 19 , with a mean age of $9.07(S D=4.12)$. Sample sizes ranged from 18 to 541 .

The first author extracted study characteristics as well as data for calculation of effect sizes and contacted authors of primary studies for additional data where needed. Study characteristics were also extracted from 11 randomly selected effect sizes (18\% of the effect sizes from the studies identified during the original search) by another author. The two authors agreed on 287 out of 297 study characteristics items (97\%). All discrepancies were resolved by a simultaneous joint review of the studies in question. 


\section{Coding of Effect Sizes}

We calculated Cohen's $d$ as the measure of the difference in cooperation between ingroup and outgroup. Cohen's $d$ is the difference between two means divided by the pooled standard deviation. We then converted Cohen's $d$ into Hedges's $g$ to prevent overestimation of effect sizes in small samples (Borenstein et al., 2009). If means and standard deviations were not provided, we derived Cohen's $d$ from an $F$ score (for one effect size) or rates of cooperative behaviour (for 24 effect sizes). Details concerning effect size calculations are in the Supplemental Material (SM4, https://osf.io/6xu9q).

A positive $d$ value indicated that cooperation (i.e., donations in a (mini-)dictator game, the amount given in a prisoner's dilemma game, investments or returns in a trust game, and offers in an ultimatum game) was higher when the partner was from an ingroup than if they were from an outgroup. Conversely, a negative $d$ value indicated that cooperation was higher when the partner was from an outgroup than if they were from an ingroup. A null $d$ value indicated no intergroup discrimination, and the closer the $d$ value to zero, the less discrimination there was in either direction.

For two studies that employed a within-subjects design $(k=4)$, we were unable to obtain the correlation between the ingroup and the outgroup condition for the dependent measure of cooperation. We estimated the correlation at .45 by averaging the correlations reported in the studies from our meta-analysis sample that used the same economic game. The majority of participants included in this meta-analysis played only one economic game, and thus contributed to one effect size only. However, for four studies (Angerer et al., 2016; Gummerum et al., 2009; Hermes et al., 2019; Meier et al., 2016), we coded several effect sizes which involved the same participants and sometimes the same economic game as well. The dataset and the codebook are available at https://osf.io/4e9pm/.

\section{Coding of Study Characteristics}

For each study characteristic, we report the number of ingroup versus outgroup comparisons that were coded $(k)$ in the dataset. Table 2 provides an overview of all the 
studies, dependent variables, and moderators of the 69 effect sizes included in this metaanalysis.

\section{Participant Characteristics}

We coded participants' age as the mean age of the sample for those studies that reported it and the midpoint for studies that reported age ranges only.

We coded the variable "sex" by noting the proportion of boys in the sample $(0.00=$ all girls, $1.00=$ all boys; $M=0.488 ; S D=0.140$; excluding missing sex values, $k=8$ ). A few effect sizes only included girls $(k=2)$ or boys $(k=2)$. For studies reporting only the overall percentage of boys in the entire sample, we generalized the overall percentage to each of the subsamples.

We also coded the country of participants. Participants were from twelve different countries, including Australia $(k=2)$, Austria $(k=5)$, Canada $(k=1)$, China $(k=5)$, Georgia $(k=6)$, Germany $(k=8)$, Israel $(k=10)$, Italy $(k=20)$, Slovakia $(k=2)$, South Africa $(k=4)$, Switzerland $(k=3)$, and the United States $(k=3)$.

\section{Economic Task Characteristics}

We coded whether the effect size was derived from dictator games $(k=16)$, minidictator games $(k=19)$, ultimatum games $(k=5)$, trust games $(k=8)$, prisoner's dilemma games $(k=18)$ or public goods games $(k=2)$ ("game type" variable). One study could not be classified as any of the above games and was coded as "other" $(k=1)$. This study (Do \& Telzer, 2019) employed a paradigm that most closely resembled the mini-dictator game. However, delivering a benefit to the partner led to disadvantageous inequality (e.g., choosing $[0,2]$ over $[1,0])$.

Participants almost always interacted in a dyad with only one other person $(k=67)$ and only twice in a group (of four persons; $k=2$ ). In almost all of the studies, participants interacted once $(k=61)$. In studies with repeated interactions, participants usually interacted between two and five times and were assigned the same partner each time $(k=7)$. The exception is one fMRI study $(k=1)$, where participants interacted thirty times, with a new partner each time. 
The effects sizes were further classified according to whether they were derived from economic games without outcome interdependence (dictator-type games; $k=36$ ) or from economic games that contain outcome interdependence (ultimatum games, trust games, prisoner's dilemma games, and public goods dilemma games; $k=33$ ) (“interdependence” variable). Among the latter, some games involved simultaneous $(k=17)$ and some sequential decisions $(k=16$; including both first-mover, $k=9$, and second-mover decisions, $k=7)$.

\section{Additional Study Characteristics}

We coded whether the study used natural $(k=54)$ or experimentally created $(k=15)$ group membership ("group type” variable). Most natural group categories were based on school identity $(k=40)$, that is, the ingroup belonged to the same class $(k=17)$ or the same school $(k=23)$ as the participant. Fewer studies explored race $(k=6)$, language $(k=5)$, ethnicity $(k=2)$ or within-country state affiliation $(k=1)$. All of the studies using experimentally created groups employed the "minimal group" paradigm (i.e., participants were divided into groups randomly or on inessential grounds) (Tajfel et al., 1971).

Next, we coded whether group membership was manipulated between- $(k=40)$ or within-subjects $(k=29)$ (“membership manipulation” variable).

We also coded whether the rewards exchanged during the game were monetary $(k=$ 23) or non-monetary $(k=46)$ ("reward type" variable). As opposed to studies that used monetary units in the country's official currency, non-monetary rewards often included tokens $(k=22)$, which children exchanged for different kinds of non-monetary goods, such as sweets, fruit or toys. Other non-monetary rewards included sweets $(k=11)$, stickers $(k=$ $9)$, toy coins $(k=2)$ or a combination of those $(k=2)$. In the majority of studies the personal cost to cooperate was real $(k=67)$ and hypothetical in only one study $(k=2)$.

Common to this line of research, studies involved relatively anonymous interactions and participants received only minimal information about their partner. In all studies $(k=69)$, participants knew that their partner was their age-peer. The partner's sex, however, was almost always hidden $(k=50)$ or not controlled for $(k=12)$; in the rest of the studies $(k=7)$ 
participants were assigned a same-sex partner. The partner was never physically or virtually present during the experiment $(k=69)$.

\section{Table 2}

\section{Effect Sizes Included in the Meta-Analysis}

\begin{tabular}{|c|c|c|c|c|c|c|c|c|}
\hline \multirow[b]{2}{*}{ Effect size ${ }^{a}$} & \multicolumn{4}{|c|}{ Participant characteristics } & \multicolumn{4}{|c|}{ Study characteristics } \\
\hline & $N$ & $\begin{array}{c}\text { Age } \\
\text { (years) }\end{array}$ & Sex & $\mathrm{CO}$ & Group & Game & Rwd & Manip. \\
\hline Angerer et al. (2016) - S1 - G1a & 135 & 6.62 & 0.59 & IT & $\mathrm{N}$ & PD & non\$ & WS \\
\hline Angerer et al. (2016) - S1 - G1b & 135 & 6.62 & 0.59 & IT & $\mathrm{N}$ & PD & non\$ & WS \\
\hline Angerer et al. (2016) - S2 - G1a & 180 & 7.79 & 0.59 & IT & $\mathrm{N}$ & PD & non\$ & WS \\
\hline Angerer et al. (2016) - S2 - G1b & 180 & 7.79 & 0.59 & IT & $\mathrm{N}$ & PD & non\$ & WS \\
\hline Angerer et al. (2016) - S3 - G1a & 162 & 8.86 & 0.54 & IT & $\mathrm{N}$ & PD & non\$ & WS \\
\hline Angerer et al. (2016) - S3 - G1b & 162 & 8.86 & 0.54 & IT & $\mathrm{N}$ & PD & non\$ & WS \\
\hline Angerer et al. (2016) - S4 - G1a & 155 & 9.87 & 0.55 & IT & $\mathrm{N}$ & PD & non\$ & WS \\
\hline Angerer et al. (2016) - S4 - G1b & 155 & 9.87 & 0.55 & IT & $\mathrm{N}$ & PD & non\$ & WS \\
\hline Angerer et al. (2016) - S5 - G1a & 196 & 10.80 & 0.47 & IT & $\mathrm{N}$ & PD & non\$ & WS \\
\hline Angerer et al. (2016) - S5 - G1b & 196 & 10.80 & 0.47 & IT & $\mathrm{N}$ & PD & non\$ & WS \\
\hline Bauer et al. (2013) - S1 & 118 & 8.62 & NA & GR & $\mathrm{N}$ & MDG & non\$ & BS \\
\hline Bauer et al. (2013) - S2 & 184 & 9.14 & NA & GR & $\mathrm{N}$ & MDG & non\$ & BS \\
\hline Bauer et al. (2013) - S3 & 75 & 8.83 & NA & GR & N & MDG & non\$ & BS \\
\hline Bauer et al. (2013) - S4 & 62 & 5.34 & NA & GR & $\mathrm{N}$ & MDG & non\$ & BS \\
\hline Bauer et al. (2013) - S5 & 66 & 5.33 & NA & GR & $\mathrm{N}$ & MDG & non\$ & BS \\
\hline Bauer et al. (2013) - S6 & 60 & 5.35 & NA & GR & $\mathrm{N}$ & MDG & non\$ & BS \\
\hline Bauer et al. (2018) - S1 - G1a & 74 & 13.95 & 0.57 & SK & $\mathrm{N}$ & PD & non\$ & WS \\
\hline Bauer et al. (2018) - S2 - G1b & 105 & 13.71 & 0.49 & SK & $\mathrm{N}$ & PD & non\$ & WS \\
\hline Benozio \& Diesendruck (2015) - S1 & 123 & 5.00 & 1.00 & IL & E & DG & non\$ & WS \\
\hline Benozio \& Diesendruck (2015) - S2 & 105 & 5.00 & 0.00 & IL & $E$ & DG & non\$ & WS \\
\hline Benozio \& Diesendruck (2015) - S3 & 65 & 5.00 & 1.00 & IL & $E$ & DG & non\$ & WS \\
\hline Benozio \& Diesendruck (2015) - S4 & 76 & 5.00 & 0.00 & IL & $E$ & DG & non\$ & WS \\
\hline Böhm \& Buttelmann (2017) - S1 & 52 & 6.08 & 0.54 & DE & E & $D G$ & non\$ & WS \\
\hline Böhm \& Buttelmann (2017) - S2 & 40 & 7.83 & 0.58 & DE & E & $D G$ & non\$ & WS \\
\hline Burns (2012) - S1 & 70 & 16.50 & 0.50 & SA & $\mathrm{N}$ & TG & $\$$ & BS \\
\hline Burns (2012) - S2 & 99 & 16.50 & 0.50 & SA & $\mathrm{N}$ & TG & $\$$ & BS \\
\hline Burns (2012) - S3 & 52 & 16.50 & 0.50 & SA & $\mathrm{N}$ & TG & $\$$ & BS \\
\hline Burns (2012) - S4 & 87 & 16.50 & 0.50 & SA & $\mathrm{N}$ & TG & $\$$ & BS \\
\hline Chiang \& Wu (2015) & 541 & 10.19 & 0.51 & $\mathrm{CN}$ & $N$ & $D G$ & non\$ & WS \\
\hline Do \& Telzer (2019) & 51 & 12.94 & 0.45 & US & $\mathrm{N}$ & $\mathrm{O}$ & non\$ & WS \\
\hline Fehr et al. (2008) - S1 & 50 & 3.50 & 0.45 & $\mathrm{CH}$ & $N$ & MDG & non\$ & BS \\
\hline Fehr et al. (2008) - S2 & 74 & 5.50 & 0.45 & $\mathrm{CH}$ & $N$ & MDG & non\$ & BS \\
\hline Fehr et al. (2008) - S3 & 105 & 7.50 & 0.45 & $\mathrm{CH}$ & $N$ & MDG & non\$ & BS \\
\hline Fehr et al. (2013) - S1 & 71 & 9.37 & 0.56 & AT & $\mathrm{N}$ & MDG & $\$$ & BS \\
\hline Fehr et al. (2013) - S2 & 207 & 11.30 & 0.43 & AT & $N$ & MDG & $\$$ & BS \\
\hline Fehr et al. (2013) - S3 & 172 & 13.37 & 0.47 & AT & $\mathrm{N}$ & MDG & $\$$ & BS \\
\hline
\end{tabular}




\begin{tabular}{|c|c|c|c|c|c|c|c|c|}
\hline \multirow[b]{2}{*}{ Effect size ${ }^{a}$} & \multicolumn{4}{|c|}{ Participant characteristics } & \multicolumn{4}{|c|}{ Study characteristics } \\
\hline & $N$ & $\begin{array}{c}\text { Age } \\
(\text { years) }\end{array}$ & Sex & $\mathrm{CO}$ & Group & Game & Rwd & Manip. \\
\hline Fehr et al. (2013) - S4 & 135 & 15.29 & 0.32 & AT & $\mathrm{N}$ & MDG & $\$$ & BS \\
\hline Fehr et al. (2013) - S5 & 132 & 17.26 & 0.48 & AT & $\mathrm{N}$ & MDG & $\$$ & BS \\
\hline Gummerum et al. (2009) - S1 - G1 & 81 & 7.10 & 0.46 & DE & E & DG & $\$$ & BS \\
\hline Gummerum et al. (2009) - S1 - G2 & 81 & 7.10 & 0.46 & $\mathrm{DE}$ & E & PD & $\$$ & BS \\
\hline Gummerum et al. (2009) - S2 - G1 & 75 & 11.60 & 0.44 & DE & E & DG & $\$$ & BS \\
\hline Gummerum et al. (2009) - S2 - G2 & 75 & 11.60 & 0.44 & DE & $E$ & PD & $\$$ & BS \\
\hline Hermes et al. (2019) - S1 - G1a & 129 & 6.00 & 0.49 & DE & $E$ & PGD & non\$ & BS \\
\hline Hermes et al. (2019) - S1 - G1b & 129 & 6.00 & 0.49 & DE & $E$ & PGD & non\$ & BS \\
\hline Kogut (2012) - S1 & 57 & 5.50 & 0.51 & IL & $\mathrm{N}$ & DG & non\$ & BS \\
\hline Kogut (2012) - S2 & 67 & 7.50 & 0.51 & IL & $\mathrm{N}$ & DG & non\$ & BS \\
\hline Kogut (2012) - S3 & 57 & 9.50 & 0.51 & IL & $\mathrm{N}$ & DG & non\$ & BS \\
\hline Kogut (2012) - S4 & 62 & 5.50 & 0.51 & IL & $\mathrm{N}$ & UG & non\$ & BS \\
\hline Kogut (2012) - S5 & 53 & 7.50 & 0.51 & IL & $\mathrm{N}$ & UG & non\$ & BS \\
\hline Kogut (2012) - S6 & 49 & 9.50 & 0.51 & IL & $\mathrm{N}$ & UG & non\$ & BS \\
\hline List et al. (2017) - S1 & 39 & 4.30 & NA & $A U$ & $\mathrm{~N}$ & DG & non\$ & WS \\
\hline List et al. (2017) - S2 & 18 & 4.30 & NA & $\mathrm{AU}$ & N & $D G$ & non\$ & WS \\
\hline McAuliffe \& Dunham (2017) - S1 & 44 & 6.76 & 0.47 & US & $E$ & UG & non\$ & WS \\
\hline McAuliffe \& Dunham (2017) - S2 & 52 & 9.27 & 0.47 & US & $E$ & UG & non\$ & WS \\
\hline Meier et al. (2016) - S1 - G1a & 257 & 17.73 & 0.45 & IT & $\mathrm{N}$ & TG & $\$$ & BS \\
\hline Meier et al. (2016) - S1 - G1b & 255 & 17.73 & 0.45 & IT & $\mathrm{N}$ & $\mathrm{TG}$ & $\$$ & BS \\
\hline Meier et al. (2016) - S1 - G2a & 257 & 17.73 & 0.45 & IT & $\mathrm{N}$ & PD & $\$$ & BS \\
\hline Meier et al. (2016) - S1 - G2b & 257 & 17.73 & 0.45 & IT & $\mathrm{N}$ & PD & $\$$ & BS \\
\hline Meier et al. (2016) - S1 - G3 & 257 & 17.73 & 0.45 & $\mathrm{IT}$ & $\mathrm{N}$ & DG & $\$$ & BS \\
\hline Meier et al. (2016) - S2 - G1a & 187 & 16.97 & 0.38 & IT & $\mathrm{N}$ & $\mathrm{TG}$ & $\$$ & BS \\
\hline Meier et al. (2016) - S2 - G1b & 187 & 16.97 & 0.38 & IT & $\mathrm{N}$ & $\mathrm{TG}$ & $\$$ & BS \\
\hline Meier et al. (2016) - S2 - G2a & 186 & 16.97 & 0.38 & IT & $\mathrm{N}$ & PD & $\$$ & BS \\
\hline Meier et al. (2016) - S2 - G2b & 186 & 16.97 & 0.38 & IT & $\mathrm{N}$ & PD & $\$$ & BS \\
\hline Meier et al. (2016) - S2 - G3 & 187 & 16.97 & 0.38 & IT & $\mathrm{N}$ & DG & $\$$ & BS \\
\hline Sparks et al. (2017) & 40 & 4.92 & 0.53 & $\mathrm{CA}$ & $E$ & MDG & non\$ & WS \\
\hline Yu et al. (2016) - S1 & 32 & 4.17 & 0.50 & $\mathrm{CN}$ & $\mathrm{N}$ & MDG & non\$ & WS \\
\hline Yu et al. (2016) - S2 & 32 & 5.93 & 0.47 & $\mathrm{CN}$ & $\mathrm{N}$ & MDG & non\$ & WS \\
\hline Yu et al. (2016) - S3 & 32 & 7.26 & 0.56 & $\mathrm{CN}$ & $\mathrm{N}$ & MDG & non\$ & WS \\
\hline Yu et al. (2016) - S4 & 26 & 9.12 & 0.54 & $\mathrm{CN}$ & $\mathrm{N}$ & MDG & non\$ & WS \\
\hline
\end{tabular}

Note. $N$ = sample size; Sex = the proportion of boys; $\mathrm{CO}=$ country; $\mathrm{DE}=$ Germany; $\mathrm{CH}=$ Switzerland; AT = Austria; US = USA; IL = Israel; IT = Italy; CN = China; GR = Georgia; SA = South Africa; $A U$ = Australia; $\mathrm{CA}=$ Canada; $\mathrm{SK}=$ Slovakia; Group = group type; $\mathrm{E}=$ experimentally created groups; $\mathrm{N}=$ natural groups; Game = game type; $P D=$ prisoner's dilemma game; $D G=$ dictator game; $M D G=$ minidictator game; $\mathrm{TG}=$ trust game; $\mathrm{UG}=$ ultimatum game; $\mathrm{PGD}=$ public goods dilemma game; $\mathrm{O}=$ other; $\mathrm{Rwd}=$ reward type; $\$=$ monetary rewards; non $\$=$ non-monetary rewards; Manip. = group membership manipulation; $\mathrm{BS}=$ between-subjects design; $\mathrm{WS}=$ within-subjects design .

a For studies with multiple subsamples, the result of each subsample (S1, S2, etc.) is reported separately, and for studies with multiple economic games, the result for each economic game (G1, G2, etc.) - sometimes played under modified conditions (G1a, G1b, etc.) - is reported separately.

${ }^{b}$ When the mean age was not provided, we coded the midpoint of the age range. 


\section{Results}

\section{Analytic Strategy}

One of the assumptions in meta-analysis is the independence of individual effect sizes. However, in our dataset, effect size dependence was present at several levels some papers reported multiple studies, some studies included several subsamples, and some effect sizes were obtained on the same subsample. To account for effect size dependence, we fit a multilevel meta-analytic model including random effects at the following, nested levels (from the highest-order to the lowest-order): paper, study, subsample, and effect size. Moreover, to address the issue of multiple effect sizes coming from the same group of participants, we constructed the covariance matrix, setting the correlation to $.60^{3}$. Finally, we used robust variance estimation (RVE) with small-sample corrections proposed by Tipton (2015) and Tipton and Pustejovsky (2015) to obtain standard errors and confidence intervals for the estimated effect size. The same analytic approach was used for estimating both the overall effect and the effects of moderator variables.

To assess the amount of heterogeneity present in the data, we inspected the $Q, I^{2}$, and $\sigma^{2}$ statistics. The $Q$ statistic tests the null hypothesis that there is no heterogeneity in the data; the $l^{2}$ statistic provides the percentage of effect size variance that can be attributed to heterogeneity; the $\sigma^{2}$ statistics refer to variances at each of the random-effect levels. By summing these variance components, we can obtain the estimated amount of total heterogeneity present in the data.

We also estimated the retrospective statistical power for the overall effect size analysis. To our knowledge, procedures for calculating power for a multilevel meta-analysis have not yet been developed. Therefore, when conducting this analysis, we assumed that all effect sizes were mutually independent, and thus our results should be treated as an approximation only.

Since the majority of publication bias estimation techniques are univariate and assume effect size independence, they were not appropriate for our data. Following the 
recommendations of Rodgers and Pustejovsky (2020), we performed a multi-level Egger's test (with RVE) and the Vevea and Hedges (1995) sensitivity model on both an aggregated dataset and a dataset with one randomly selected effect size from each paper (both approaches satisfy the assumption of effect size independence). Additionally, we performed a p-uniform* sensitivity analysis (van Aert \& van Assen, 2020) on the two reduced datasets. When aggregating effect sizes from the same paper, we assumed a correlation of .50 . We also inspected the contour-enhanced funnel plot (Peters et al., 2008). Finally, we inspected the data for outliers and influential cases using studentised residuals and Cook's distance.

Some of the moderators in our study were mutually correlated (game type and interdependence) and therefore could not be included in the analysis simultaneously. Moreover, not all moderators could be tested on the full dataset. One study (Do \& Telzer, 2019) was excluded while analysing the game type moderator to ensure that all levels were represented by more than one effect size. When analysing the moderating effect of sex, we excluded studies that did not report the percentage of boys or girls in the sample, and, when testing the moderating effect of age, we excluded two studies (Chiang \& Wu, 2015; Do \& Telzer, 2019) due to their extensive age range spanning from childhood to adolescence. With this in mind, to maximize the sample size when testing for moderator effects, we ran nine single moderator analyses.

All analyses were done in $R$ ( $R$ Core Team, 2020). We specified all models using the metafor package (Version 2.0; Viechtbauer, 2010); created the covariance matrix and obtained robust variance estimation via the clubSandwich package (Pustejovsky, 2021); calculated power using the metapower package (Griffin, 2020); aggregated effect sizes using the MaD package (Del Re \& Hoyt, 2014); conducted the Vevea and Hedges (1995) sensitivity analysis in the weightr package (Coburn \& Vevea, 2019) and p-uniform analysis using the puniform package (van Aert, 2021). The analysis script is available in the Supplemental Material (SM5, https://osf.io/6xu9q). 


\section{Overall Effect Size}

The studies included in this meta-analysis suggested a small positive effect size, indicating parochialism, $d=0.22,95 \% \mathrm{Cl}[.07, .38], k=69, p=.007$.

As shown in the forest plot in Figure 2, there were a total of 24 negative effect sizes indicating more cooperation with outgroups than with ingroups, whereas a total of 45 positive effect sizes indicated more cooperation with ingroups than with outgroups. The estimated total amount of heterogeneity was 0.086 , of which 0.08 was the variance at the level of the paper (between-paper heterogeneity) and 0.006 the variance at the level of individual effect sizes. The estimated variance components at the study and subsample levels were zero. This pattern of results is likely due to only a few papers with more than one study and only a few studies with multiple subsamples. The $Q$ and $P^{2}$ statistics indicated a substantial amount of heterogeneity in the data, $Q(d f=68)=364.44, p<.001, l^{2}=85.01 \%$ (79.23\% at the paper level and $5.78 \%$ at the effect size level), suggesting the potential role of moderating variables. 
Figure 2

Forest Plot

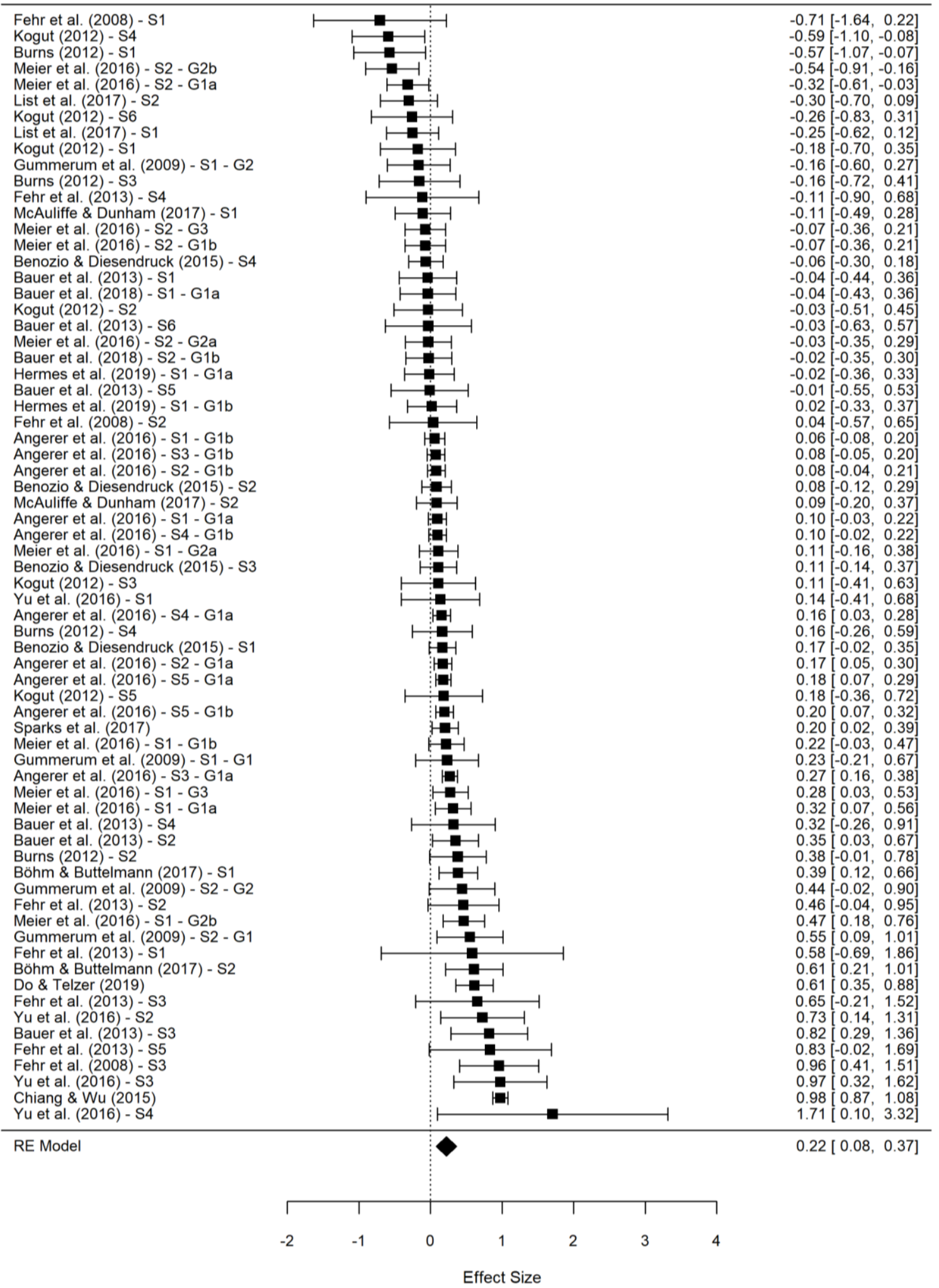




\section{Retrospective Power Calculation}

Given the number of effect sizes we identified $(k=69)$, each with an average of 82.29 participants per group, and large levels of heterogeneity $(R=85 \%)$, the power to detect the average observed effect size (0.22) for a random-effects model was $89.08 \%$ and good.

\section{Assessment of Publication Bias}

The inspection of the funnel plot (Figure 3) did not seem to indicate asymmetry. The multi-level Egger's regression test with RVE showed no funnel plot asymmetry, $z=-0.58, p$ $=.32$. The Vevea and Hedges (1995) sensitivity analysis further confirmed this. The Likelihood Ratio Test did not indicate that significant results were more likely to be published than non-significant results: $\mathcal{X}^{2}(1)=0.75, p=.39$ for the aggregated dataset and $\mathcal{X}^{2}(1)=$ $0.24, p=.62$ for the dataset with randomly sampled effect sizes. Similarly, the $p$-uniform* sensitivity analysis estimated the overall effect size corrected for publication bias to be $d=$ $.30,95 \% \mathrm{Cl}[.05, .56], p=.02$ for the aggregated and $d=.26,95 \% \mathrm{Cl}[-.03, .57], p=.07$ for the randomly sampled dataset. Based on these results, we concluded that there was no publication bias in the data. 


\section{Figure 3}

Contour Enhanced Funnel Plot

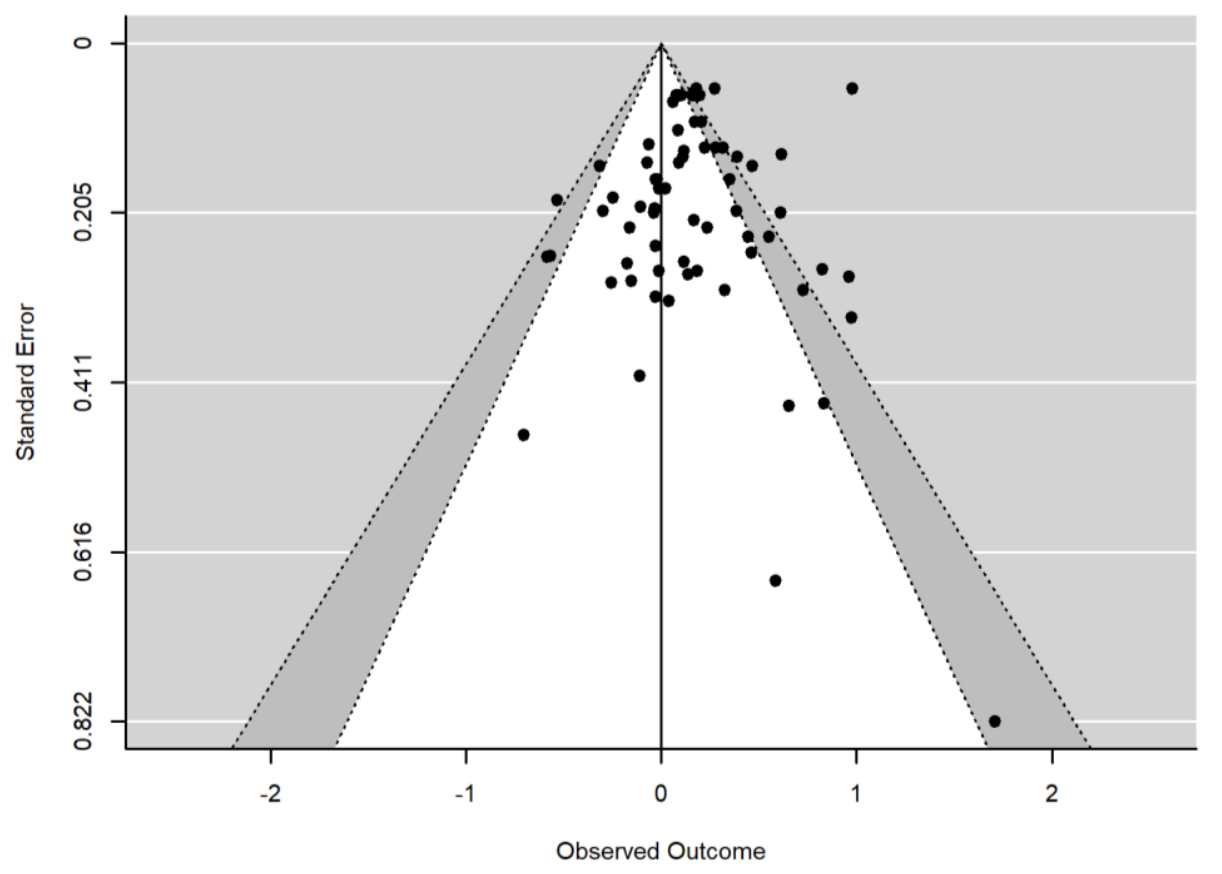

Note. The shaded area corresponds to $p$-values between .05 and .01 .

Using studentised residuals and Cook's distance, we identified one outlier / influential effect size. This was the single effect size from the Chiang and Wu 2015 study (studentised residual $z=3.72$, Cook's distance $=0.56$ ). It should be noted that this study did not differ substantially from the nearby studies in terms of the effect size (it was the second largest effect size, with the two following effect sizes being smaller by only .01 each). However, this effect size was obtained on more than twice as many participants as any other effect size, resulting in a very precise effect size estimate (as can be seen in Figure 2). Most importantly, even though the overall effect size drops to $d=0.17,95 \% \mathrm{Cl}[.05, .29], k=68, p$ $=.008$ after removing this study, its magnitude remains roughly the same. Based on this, we decided to keep the study in the dataset for further analyses.

\section{Moderator Analyses}

Since the amount of heterogeneity present in the data was substantial, we proceeded to test several potential moderators in single moderator analyses. The results are provided in Table 3. 


\section{Table 3}

Single Moderator Analyses for the Multilevel Model with Robust Variance Estimation

\begin{tabular}{|c|c|c|c|c|c|c|}
\hline Moderator & $k$ & $Q M(d f)$ & $2^{2}$ & $\mathrm{ES} d / b$ & $95 \% \mathrm{Cl}$ & $p$ \\
\hline$\overline{\mathrm{Age}}$ & $67^{a}$ & $2.85(1)$ & 73.52 & 0.02 & {$[-0.004 ; 0.04]$} & .09 \\
\hline Game type & $68^{b}$ & $6.48(5)$ & 83.47 & & & .26 \\
\hline Dictator game & 16 & & & 0.24 & {$[0.04 ; 0.51]$} & .08 \\
\hline Mini-dictator game & 19 & & & 0.36 & {$[0.14 ; 0.58]$} & .01 \\
\hline Prisoner's dilemma & 18 & & & 0.10 & {$[-0.13 ; 0.33]$} & .32 \\
\hline Public goods dilemma & 2 & & & 0.00 & {$[0.00 ; 0.00]$} & $<.001$ \\
\hline Trust game & 8 & & & 0.13 & {$[-0.16 ; 0.42]$} & .26 \\
\hline Ultimatum game & 5 & & & -0.02 & {$[-0.68 ; 0.64]$} & .83 \\
\hline Interdependence & 69 & $5.99(1)$ & 81.85 & & & .01 \\
\hline Absent & 36 & & & 0.29 & {$[0.11 ; 0.46]$} & .003 \\
\hline Present & 33 & & & 0.12 & {$[-0.04 ; 0.28]$} & .12 \\
\hline Interdependence (exp. groups) & 15 & $4.82(1)$ & 38.24 & & & .03 \\
\hline Absent & 9 & & & 0.24 & {$[-0.02,0.51]$} & .06 \\
\hline Present & 6 & & & 0.17 & {$[-0.10,0.14]$} & .62 \\
\hline Membership manipulation & 69 & $0.77(1)$ & 85.10 & & & .38 \\
\hline Between subjects & 40 & & & 0.15 & {$[-0.01 ; 0.31]$} & .06 \\
\hline Within subjects & 29 & & & 0.28 & {$[0.01 ; 0.55]$} & .04 \\
\hline Group type & 69 & $0.24(1)$ & 85.59 & & & .62 \\
\hline Experimental & 15 & & & 0.17 & {$[-0.01 ; 0.34]$} & .06 \\
\hline Natural & 54 & & & 0.25 & {$[0.02 ; 0.48]$} & .04 \\
\hline Reward type & 69 & $0.04(1)$ & 85.78 & & & .84 \\
\hline Monetary & 23 & & & 0.19 & {$[-0.10 ; 0.49]$} & .12 \\
\hline Non-monetary & 46 & & & 0.23 & {$[0.03 ; 0.43]$} & .03 \\
\hline Sex (\% of males in the sample) & $61^{c}$ & $0.99(1)$ & 85.71 & 0.13 & {$[-0.32 ; 0.58]$} & .32 \\
\hline Country & 69 & $23.55(11)$ & 74.28 & & & .01 \\
\hline Austria & 5 & & & 0.45 & {$[0.19,0.71]$} & .03 \\
\hline Australia & 2 & & & -0.27 & {$[-0.33,-0.22]$} & .01 \\
\hline Canada & 1 & & & 0.21 & - & \\
\hline Switzerland & 3 & & & 0.33 & {$[-3.27,3.93]$} & .45 \\
\hline China & 5 & & & 0.83 & {$[-1.31,2.97]$} & .13 \\
\hline Germany & 8 & & & 0.25 & {$[-0.33,0.84]$} & .20 \\
\hline Georgia & 6 & & & 0.24 & {$[-0.10,0.58]$} & .07 \\
\hline Israel & 10 & & & -0.01 & {$[-1.33,1.30]$} & .92 \\
\hline Italy & 20 & & & 0.11 & {$[-0.27,0.50]$} & .16 \\
\hline South Africa & 4 & & & 0.03 & {$[-2.70,2.75]$} & .93 \\
\hline Slovakia & 2 & & & -0.03 & {$[-0.06,0.01]$} & .06 \\
\hline United States & 3 & & & 0.30 & {$[-3.53,4.12]$} & .50 \\
\hline
\end{tabular}

Note. exp. groups = experimental groups; $k=$ number of ingroup-outgroup comparisons; $Q M(d f)=$ model fit $Q$ statistic with its degrees of freedom (in the brackets); $R=$ percentage of residual heterogeneity; ES $d / b=$ Effect size: Cohen's $d$ in case of categorical moderators and regression slope (b) in case of continuous moderators; $\mathrm{Cl}=$ confidence interval; $p=$ significance of model.

a Chiang and Wu (2015) and Do and Telzer (2019) studies were excluded from the analysis due to the wide age range.

${ }^{\mathrm{b}}$ Do and Telzer (2019) study was excluded from the analysis to ensure that all levels of the game type moderator were represented by more than one effect size.

${ }^{c}$ Eight effect sizes excluded due to missing information on gender. 
Before fitting any age-related models, we inspected the scatter plot of the relation between participant age and effect size (see Supplemental Material, SM6, https://osf.io/6xu9q). Since the scatter plot did not indicate a non-linear relation, we decided to test only for the linear effect of age on parochialism. This revealed that parochial cooperation did not vary with participants' age.

There were no differences in parochialism between different economic game types. However, the meta-analytically estimated effect size was larger for games without interdependence compared to games with interdependence. Since naturally created groups do not exclude the possibility of real interdependence outside of the experimental situation, we repeated this analysis using only experimentally created groups. Parochialism was again larger when participants played games without interdependence. Due to a small number of effect sizes $(k=15)$, however, these results should be taken with caution.

We did not register any moderating effects of membership manipulation, group type, reward type or sex. Although there appeared to be some systematic variation between countries, due to the small number and uneven distribution of effect sizes per country, these findings should be viewed only as preliminary.

\section{Discussion}

The present meta-analysis aimed to examine the extent of parochialism in cooperative decision-making of children and adolescents and to evaluate the potential role of several moderating variables. In answer to the first research question, we found a small positive effect $(d=0.22,95 \% \mathrm{Cl}[.07, .38])$, suggesting that children and adolescents are somewhat more willing to incur a personal cost to provide benefits to another ingroup member, compared to another outgroup member.

This effect is lower than the one found in the meta-analysis by Balliet, Wu, and De Dreu (2014), which would suggest that parochialism in cooperation becomes more pronounced in adulthood $(d=0.32)$. Even though the eligibility criteria in the two metaanalyses were identical (except for participants' age), certain methodological differences between the sampled studies preclude a definitive interpretation. Most notably, adults 
played interdependent games more than three times more often than non-interdependent games, while children and adolescents in the studies we sampled played interdependent games roughly as frequently as non-interdependent games. Furthermore, adults played various types of social dilemma games (including prisoner's, public goods, and resource dilemmas). Children and adolescents, on the other hand, were typically presented only with prisoner's dilemma games, and with a public goods game in only one study (Hermes et al., 2019). Regarding the nature of group membership, while the studies with adults featured an almost equal number of naturally-occurring and experimentally created groups, the studies we sampled overwhelmingly used natural groups (e.g., school identity, race, language).

We did not find evidence of publication bias in the studies included in this metaanalysis. In other words, there was no reason to assume a large body of unpublished results indicating the absence of parochialism or even the existence of some type of outgroup favouritism exists in this field. Twenty-four effect sizes indeed pointed to more cooperation with outgroups than with ingroups, leading us to believe the overall effect size we obtained was a good estimate of the population value.

\section{The Role of Moderators}

\section{Participant Characteristics}

Even though some primary studies (Angererer et al., 2016; Fehr et al., 2008, 2013) reported that children and adolescents became more parochial with increasing age, the present meta-analysis found no support for this conclusion. Our finding that parochialism in cooperation did not vary with participants' age should be, however, viewed only as preliminary due to several limitations of the included studies. The age ranges used were very heterogeneous - as narrow as 5.50-6.42 and as wide as 7-12. Thus, it is possible that some age differences were partially masked by the imprecision of the sample age estimate that could be extracted from the studies. Moreover, there was a discrepancy in the number of participants from different age ranges. Around half of participants (and ingroup versus outgroup comparisons) came from the middle childhood age group, with children under 6 and adolescents over 12 years of age being relatively underrepresented. 
Regarding sex differences, although Balliet, Wu, and De Dreu (2014) found that parochialism tended to be higher in studies with more men compared to women, we found no differences between boys and girls. An in-depth investigation of sex and gender differences in parochialism might also need to account for the presence or absence of strategic considerations (Sutter et al., 2019) and competitive pressure (Houser \& Schunk, 2009 ) in economic games, as well as for the partner's personal preferences regarding the resource (Benozio \& Diesendruck, 2015).

Although our findings revealed some cross-national variation in parochial cooperation among children and adolescents, this analysis was exploratory only and the findings would need to be replicated in large-scale multinational or cross-cultural studies with an even distribution of participants.

\section{Economic Game and Other Study Characteristics}

We found some indication that outcome interdependence might moderate parochialism. In contrast to the (bounded) reciprocity perspective and to what was observed among adults (Balliet, Wu et al., 2014), children and adolescents seemed to be more cooperative toward ingroups versus outgroups when playing non-interdependent games (i.e., dictator-type games) compared to interdependent games (i.e., bargaining and social dilemma games). In other words, being mutually dependent on each other's choices seemed to decrease intergroup discrimination. It is important to note that parochialism in mini-dictator games might have contributed to this effect even more than parochialism in dictator games (Table 3). The former use a binary allocation format with a forced-choice between egalitarian and selfish decisions, which might be easier for younger children to comprehend. In the future, more research is required to disentangle the effects of group membership and interdependence on children's and adolescents' cooperative decisionmaking. For example, the possibility for direct reciprocity in repeated interactions (e.g., Axelrod \& Hamilton, 1981) may prove to be a better predictor of parochialism. Future studies could modify typical economic game designs to detect this (for example, by using games with multiple rounds). 
We did not find the artificiality of group membership (natural versus experimental groups) to moderate parochial cooperation among children and adolescents. This is in line with previous research showing that even mere categorization into groups is sufficient to induce parochialism both among children (Dunham et al., 2011; cf. Spielman, 2000) and adults (Balliet, Wu et al., 2014). Furthermore, we found no relation between either the type of group manipulation (within- versus between-subjects design) or the type of rewards that were distributed (monetary versus non-monetary rewards such as sweets or stickers) and effect size.

\section{Explaining the Heterogeneity}

Even though we included several potentially meaningful moderators of parochial cooperation in children and adolescents, we were unable to explain the large heterogeneity present in the data. Including additional moderators, however, would not have been necessarily better at explaining the observed data heterogeneity, due to the relatively small number of studies. Therefore, we should not exclude the possibility that some, or several, of the participant, economic game or study characteristics that we coded for would moderate parochial cooperation in repeated meta-analyses on larger samples of studies.

\section{Limitations}

There are three major limitations of the present meta-analysis. First, a relatively small number of studies met the inclusion criteria, which means our study was very likely underpowered to detect the effects of moderator variables. A Monte Carlo simulation study showed that meta-analyses very rarely achieve sufficient power to detect moderator effects (even large ones) - the exceptions are cases where the number of studies and the average number of participants per study are quite large, while residual heterogeneity is small (Hempel et al., 2013). In all other cases, interpreting the inability to detect a significant moderator effect as the absence of such an effect may lead to a Type II error. Second, the striking differences in age ranges across primary studies made it difficult to identify potential changes in parochialism with age. Third, the specific experimental designs and outcome variables of included studies limit the generalizability of our findings. The conclusions are 
limited to situations in which an individual distributes positive resources (rewards) between themselves and a single ingroup or outgroup member, in relatively anonymous, typically one-time, interactions.

\section{Methodological Implications for Future Experimental Economics Research}

Based on the results of our meta-analysis, we would like to make several recommendations for primary studies using economic games to explore parochialism in children and adolescents.

More than half of the studies we meta-analysed used natural group categories based on school (belonging to a school or school class). School identity and the sense of belonging to a school can differ among students, depending on characteristics such as age, grade, gender, socioeconomic status, majority or minority identity, and school size and structure (Bellmore et al., 2011; Eccles \& Roeser, 2013; Krstić et al., 2017; Wentzel, 2013). For example, while younger students might not have had enough time to develop a strong group identity, older students' school identity may have become more diffused or enlarged as they moved to higher grades. Furthermore, the social identity development theory (Nesdale, 1999, 2004) would predict that children's outgroup prejudice and discrimination depend on the strength of their identification with the ingroup (this prediction has been experimentally tested; e.g., Nesdale et al., 2003; Nesdale et al., 2005). Therefore, experimental economics studies on parochial cooperation which rely on school membership should more routinely assess the level of students' school identity or the sense of school belonging. The same recommendation also applies to other natural group memberships.

To provide more empirical data on when parochial cooperation emerges in childhood and on how it changes with age, primary studies should report age ranges more precisely and use more restricted, instead of broad, age groups.

Only one study in our sample (Gummerum et al., 2009) would allow us to additionally code findings comparing cooperation with ingroup and outgroup members to cooperation with unclassified strangers. Therefore, we were not able to explore whether parochial cooperation was a result of a positive concern for members of one's own group (ingroup 
favouritism or ingroup love) or a result of a motivation to harm the outgroup (outgroup derogation or outgroup hate) (Brewer, 1999). If motivated by ingroup favouritism, cooperation should be higher toward ingroups than toward both outgroups and strangers; if motivated by outgroup derogation, cooperation should be lower toward outgroups than toward both ingroups and strangers (Balliet, Wu et al., 2014). Buttelmann and Böhm (2014), for example, showed that ingroup favouritism was already present in 6-year-olds, whereas 8-year-olds were also motivated by outgroup derogation. To distinguish between these two types of motivation across childhood and adolescence, future studies should more often include cooperation with unclassified strangers in their design.

\section{Conclusion}

The present study was the first to meta-analytically examine parochialism in cooperative decision-making in childhood and adolescence. Similarly to what has been found in adults (Balliet, Wu et al., 2014), there was a small preference for one's own group, compared to an outgroup, in situations when children and adolescents were participating in personally costly acts of cooperation. The observed parochialism did not vary with participants' age or sex. Furthermore, there were no differences between different types of economic games. However, in contrast to the bounded reciprocity perspective, parochialism was larger in non-interdependent (dictator-type) compared to interdependent (bargaining and social dilemma) games. We did not observe any moderating effects of group type, membership manipulation or reward type. Future primary studies would benefit from making the age ranges more compressed as well as from recruiting children under 5 and adolescents over 12 years of age. Furthermore, future experimental economics studies on parochialism should take into account children's and adolescents' sense of group identity and belonging, aim for designs that include an unclassified stranger, and use repeated interaction designs more frequently. Such changes would address some important underexplored theoretical issues in the domain of parochial cooperation and would increase the applicability of findings to interventions aimed at reducing intergroup discrimination. 


\section{Endnotes}

1. Parochial cooperation is a type of intergroup discrimination when deciding to cooperate. Intergroup discrimination is any type of differential behaviour toward ingroup and outgroup members. Intergroup discrimination is encompassed under the broader term of intergroup bias (Hewstone et al., 2002). Parochial cooperation can be motivated by, and manifested in favouring ingroups (ingroup love) and derogating outgroups (outgroup hate) (De Dreu et al., 2014). In this paper, we used the term cooperation to describe cooperative behaviours that provide a benefit to another individual while being costly to the actor; in this sense, cooperation is sometimes referred to as helping or altruism (see West et al., 2007).

2. This is not to say that unclassified strangers could not be included in the study design, only that unclassified strangers were not considered to be outgroup members.

3. We ran a sensitivity analysis with correlations ranging from 0 to .90 in .10 increments and observed only minimal differences in the overall effect size estimate (.01 between the highest and the lowest obtained value). The script for this analysis is available in the Supplemental Material (SM5, https://osf.io/6xu9q). 


\section{References}

References marked with an asterisk indicate studies included in the meta-analysis.

Abrams, D., de Vyver, J., Pelletier, J., \& Cameron, L. (2015). Children's prosocial behavioural intentions towards outgroup members. British Journal of Developmental Psychology, 33(3), 277-294. https://doi.org/10.1111/bjdp.12085

*Angerer, S., Glätzle-Rützler, D., Lergetporer, P., \& Sutter, M. (2016). Cooperation and discrimination within and across language borders: Evidence from children in a bilingual city. European Economic Review, 90, 254-264.

https://doi.org/10.1016/j.euroecorev.2016.02.022

Axelrod, R., \& Hamilton, W. D. (1981). The evolution of cooperation. Science, 211(4489), 1390-1396. https://doi.org/10.1126/science.7466396

Balliet, D., Wu, J., \& De Dreu, C. K. W. (2014). In-group favoritism in cooperation: A metaanalysis. Psychological Bulletin, 140(6), 1556-1581. https://doi.org/10.1037\%2Fa0037737

*Bauer, M., Cassar, A., Chytilová, J., \& Henrich, J. (2013). War's enduring effects on the development of egalitarian motivations and in-group biases. Psychological Science, 25(1), 47-57. https://doi.org/10.1177/0956797613493444

*Bauer, M., Cahlíková, J., Chytilová, J., \& Želinský, T. (2018). Social contagion of ethnic hostility. Proceedings of the National Academy of Sciences, 115(19), 4881-4886. https://doi.org/10.1073/pnas.1720317115

Bellmore, A., Villarreal, V. M., \& Ho, A. Y. (2011). Staying cool across the first year of middle school. Journal of Youth and Adolescence, 40(7), 776-785.

https://doi.org/10.1007/s10964-010-9590-x

*Benozio, A., \& Diesendruck, G. (2015). Parochialism in preschool boys' resource allocation. Evolution and Human Behavior, 36(4), 256-264.

https://doi.org/10.1016/i.evolhumbehav.2014.12.002 
Bigler, R. S., Jones, L. C., \& Lobliner, D. B. (1997). Social categorization and the formation of intergroup attitudes in children. Child Development, 68(3), 530-543. https://doi.org/10.1111/j.1467-8624.1997.tb01956.x

*Böhm, R., \& Buttelmann, D. (2017). The impact of resource valence on children's otherregarding preferences. Developmental Psychology, 53(9), 1656-1665.

\section{https://doi.org/10.1037/dev0000365}

Borenstein, M., Hedges, L. V., Higgins, J. P., \& Rothstein, H. R. (2009). Introduction to meta-analysis. John Wiley \& Sons.

Bornstein, G. (2003). Intergroup conflict: Individual, group, and collective interests.

Personality and Social Psychology Review, 7(2), 129-145.

https://doi.org/10.1207\%2Fs15327957pspr0702 129-145

Brewer, M. B. (1999). The psychology of prejudice: Ingroup love and outgroup hate? Journal of Social Issues, 55(3), 429-444. https://doi.org/10.1111/0022-4537.00126

${ }^{*}$ Burns, J. (2012). Race, diversity and pro-social behavior in a segmented society. Journal of Economic Behavior \& Organization, 81(2), 366-378.

https://doi.org/10.1016/i.jebo.2011.11.006

Buttelmann, D., \& Böhm, R. (2014). The ontogeny of the motivation that underlies in-group bias. Psychological Science, 25(4), 921-927.

\section{https://doi.org/10.1177/0956797613516802}

${ }^{*}$ Chiang, Y.-S., \& Wu, C.-I. (2015). Social influence and the adaptation of parochial altruism: a dictator-game experiment on children and adolescents under peer influence. Evolution and Human Behavior, 36(6), 430-437. https://doi.org/10.1016/j.evolhumbehav.2015.03.007

Choi, J.-K., \& Bowles, S. (2007). The coevolution of parochial altruism and war. Science, 318(5850), 636-640. https://doi.org/10.1126\%2Fscience.1144237

Coburn, K., \& Vevea, J. L. (2019). Weightr: Estimating weight-function models for publication bias. https://CRAN.R-project.org/package=weightr 
De Dreu, C. K. W., Balliet, D., \& Halevy, N. (2014). Parochial cooperation in humans: Forms and functions of self-sacrifice in intergroup conflict. Advances in Motivation Science, 1-47. https://doi.org/10.1016/bs.adms.2014.08.001

Del Re, A. C., \& Hoyt, W. T. (2014). MAd: Meta-analysis with mean differences (R package version 0.8-2). https://cran.r-project.org/package=MAd

*Do, K. T., \& Telzer, E. H. (2019). Corticostriatal connectivity is associated with the reduction of intergroup bias and greater impartial giving in youth. Developmental Cognitive Neuroscience, 37, 100628. https://doi.org/10.1016/j.dcn.2019.100628

Dunham, Y., Baron, A. S., \& Carey, S. (2011). Consequences of "minimal" group affiliations in children. Child Development, 82(3), 793-811. https://doi.org/10.1111//.1467$\underline{8624.2011 .01577 . x}$

Eccles, J. S., \& Roeser, R. W. (2013). Schools as developmental contexts during adolescence. Journal of Research on Adolescence, 21(1), 225-241. https://doi.org/10.1111/j.1532-7795.2010.00725.x

Everett, J. A., Faber, N. S., \& Crockett, M. (2015). Preferences and beliefs in ingroup favoritism. Frontiers in Behavioral Neuroscience, 9. https://doi.org/10.3389\%2Ffnbeh.2015.00015

*Fehr, E., Bernhard, H., \& Rockenbach, B. (2008). Egalitarianism in young children. Nature, 454(7208), 1079-1083. https://doi.org/10.1038/nature07155

*Fehr, E., Glätzle-Rützler, D., \& Sutter, M. (2013). The development of egalitarianism, altruism, spite and parochialism in childhood and adolescence. European Economic Review, 64, 369-383. https://doi.org/10.1016/j.euroecorev.2013.09.006

Fiske, S. T. (2002). What we know now about bias and intergroup conflict, the problem of the century. Current Directions in Psychological Science, 11(4), 123-128. https://doi.org/10.1111\%2F1467-8721.00183

Gaertner, L., \& Insko, C. A. (2000). Intergroup discrimination in the minimal group paradigm: Categorization, reciprocation or fear? Journal of Personality and Social Psychology, 79(1), 77-94. https://doi.org/10.1037/0022-3514.79.1.77 
Griffin, J. W. (2020). metapoweR: an R package for computing meta-analytic statistical power (R package version 0.2.1). https://CRAN.R-project.org/package=metapower

Guerra, R., Rebelo, M., Monteiro, M. B., Riek, B. M., Mania, E. W., Gaertner, S. L., \& Dovidio, J. F. (2010). How should intergroup contact be structured to reduce bias among majority and minority group children? Group Processes \& Intergroup Relations, 13(4), 445-460. https://doi.org/10.1177/1368430209355651

Gummerum, M., Hanoch, Y., \& Keller, M. (2008). When child development meets economic game theory: An interdisciplinary approach to investigating social development. Human Development, 51(4), 235-261. https://doi.org/10.1159\%2F000151494

*Gummerum, M., Takezawa, M., \& Keller, M. (2009). The influence of social category and reciprocity on adults' and children's altruistic behavior. Evolutionary Psychology, 7(2), 295-316. https://doi.org/10.1177/147470490900700212

Halevy, N., Chou, E. Y., Cohen, T. R., \& Bornstein, G. (2010). Relative deprivation and intergroup competition. Group Processes \& Intergroup Relations, 13(6), 685-700. https://doi.org/10.1177\%2F1368430210371639

Hempel, S., Miles, J. N., Booth, M. J., Wang, Z., Morton, S. C., \& Shekelle, P. G. (2013). Risk of bias: A simulation study of power to detect study-level moderator effects in meta-analysis. Systematic Reviews, 2, 107. https://doi.org/10.1186/2046-4053-2-107

${ }^{*}$ Hermes, H., Hett, F., Mechtel, M., Schmidt, F., Schunk, D., \& Wagner, V. (2019). Do children cooperate conditionally? Adapting the strategy method for first-graders. Journal of Economic Behavior \& Organization.

https://doi.org/10.1016/j.jebo.2018.12.032

Hewstone, M., Rubin, M., \& Willis, H. (2002). Intergroup bias. Annual Review of Psychology, 53(1), 575-604. https://doi.org/10.1146\%2Fannurev.psych.53.100901.135109

Houser, D., \& Schunk, D. (2009). Social environments with competitive pressure: Gender effects in the decisions of German schoolchildren. Journal of Economic Psychology, 30(4), 634-641. https://doi.org/10.1016/j.joep.2009.05.002 
Killen, M., \& Verkuyten, M. (2017). The importance of social-cognitive development and the developmental context for group dynamics. Group Processes \& Intergroup Relations, 20(5), 707-718. https://doi.org/10.1177/1368430217711771

*Kogut, T. (2012). Knowing what I should, doing what I want: From selfishness to inequity aversion in young children's sharing behavior. Journal of Economic Psychology, 33(1), 226-236. https://doi.org/10.1016/j.joep.2011.10.003

Krstić, K. Stepanović Ilić, I. \& Videnović, M. (2017). Student dropout in primary and secondary education in the Republic of Serbia. Psihološka istraživanja, 20(1), 27-50. https://doi.org/10.5937/psistra1701027k

Lane, T. (2016). Discrimination in the laboratory: A meta-analysis of economics experiments. European Economic Review, 90, 375-402. https://doi.org/10.1016/j.euroecorev.2015.11.011

*List, A. J., List, J. A., \& Samek, A. (2017). Discrimination among pre-school children: Field experimental evidence. Economics Letters, 157, 159-162.

\section{https://doi.org/10.1016/j.econlet.2017.06.006}

*McAuliffe, K., \& Dunham, Y. (2017). Fairness overrides group bias in children's secondparty punishment. Journal of Experimental Psychology: General, 146(4), 485-494. https://doi.org/10.1037/xge0000244

McDonald, M. M., Navarrete, C. D., \& Van Vugt, M. (2012). Evolution and the psychology of intergroup conflict: the male warrior hypothesis. Philosophical Transactions of the Royal Society B: Biological Sciences, 367(1589), 670-679.

\section{https://doi.org/10.1098/rstb.2011.0301}

McLoughlin, N., \& Over, H. (2018). Encouraging children to mentalise about a perceived outgroup increases prosocial behaviour towards outgroup members. Developmental Science, 22(3), e12774. https://doi.org/10.1111/desc.12774

*Meier, S., Pierce, L., Vaccaro, A., \& La Cara, B. (2016). Trust and in-group favoritism in a culture of crime. Journal of Economic Behavior \& Organization, 132, 78-92. https://doi.org/10.1016/j.jebo.2016.09.005 
Moher, D., Liberati, A., Tetzlaff, J., Altman, D. G., \& The PRISMA Group. (2009). Preferred reporting items for systematic reviews and meta-analyses: The PRISMA statement. Annals of Internal Medicine, 151(4), 264-269. https://doi.org/10.7326/0003-4819$\underline{151-4-200908180-00135}$

Nesdale, D. (1999). Social identity and ethnic prejudice in children. In P. Martin \& W. Noble (Eds.), Psychology and Society (pp. 92-110). Australian Academic Press.

Nesdale, D. (2004). Social identity processes and children's ethnic prejudice. In M. Bennett \& F. Sani (Eds.), The Development of the Social Self (pp. 219-245). Psychology Press. https://doi.org/10.4324/9780203391099 chapter 8

Nesdale, D., Maass, A., Griffiths, J., \& Durkin, K. (2003). Effects of in-group and out-group ethnicity on children's attitudes towards members of the in-group and out-group. British Journal of Developmental Psychology, 21(2), 177-192. https://doi.org/10.1348/026151003765264039

Nesdale, D., Durkin, K., Maass, A., \& Griffiths, J. (2005). Threat, group identification, and children's ethnic prejudice. Social Development, 14(2), 189-205. https://doi.org/10.1111/j.1467-9507.2005.00298.x

Over, H. (2018). The influence of group membership on young children's prosocial behaviour. Current Opinion in Psychology, 20, 17-20. https://doi.org/10.1016/i.copsyc.2017.08.005

Peters, J. L., Sutton, A. J., Jones, D. R., Abrams, K. R., \& Rushton, L. (2008). Contourenhanced meta-analysis funnel plots help distinguish publication bias from other causes of asymmetry. Journal of Clinical Epidemiology, 61(10), 991-996. https://doi.org/10.1016/i.jclinepi.2007.11.010

Petersen, L.-E., Dietz, J., \& Frey, D. (2004). The effects of intragroup interaction and cohesion on intergroup bias. Group Processes \& Intergroup Relations, 7(2), 107118. https://doi.org/10.1177/1368430204041397

Pustejovsky, J. (2019). clubSandwich: Cluster-robust (sandwich) variance estimators with small-sample corrections. https://CRAN.R-project.org/package=clubSandwich 
R Core Team. (2020). R: A language and environment for statistical computing. $\mathrm{R}$ Foundation for Statistical Computing, Vienna, Austria. https://www.R-project.org/ Rodgers, M. A., \& Pustejovsky, J. E. (2020). Evaluating meta-analytic methods to detect selective reporting in the presence of dependent effect sizes. Psychological Methods. Advance online publication. https://doi.org/10.1037/met0000300

Romano, A., Balliet, D., Yamagishi, T., \& Liu, J. H. (2017). Parochial trust and cooperation across 17 societies. Proceedings of the National Academy of Sciences, 114(48), 12702-12707. https://doi.org/10.1073/pnas.1712921114

Romano, A., Sutter, M., Liu, J. H., \& Balliet, D. (2021). Political ideology, cooperation and national parochialism across 42 nations. Philosophical Transactions of the Royal Society B: Biological Sciences, 376(1822), 20200146.

https://doi.org/10.1098/rstb.2020.0146

Sierksma, J. (2018). Costs of helping only influence children's intention to help ethnic outgroup peers. Journal of Experimental Child Psychology, 173, 85-99.

\section{https://doi.org/10.1016/j.jecp.2018.03.016}

Spadaro, G., Tiddi, I., Columbus, S., Jin, S., Ten Teije, A., \& Balliet, D. (2020). The Cooperation Databank. PsyArXiv. https://doi.org/10.31234/osf.io/rveh3

*Sparks, E., Schinkel, M. G., \& Moore, C. (2017). Affiliation affects generosity in young children: The roles of minimal group membership and shared interests. Journal of Experimental Child Psychology, 159, 242-262.

https://doi.org/10.1016/j.jecp.2017.02.007

Spielman, D. A. (2000). Young children, minimal groups, and dichotomous categorization. Personality and Social Psychology Bulletin, 26(11), 1433-1441. https://doi.org/10.1177/0146167200263010

Stephan, W. G., \& Kennedy, J. C. (1975). An experimental study of interethnic competition in segregated schools. Journal of School Psychology, 13(3), 234-247. https://doi.org/10.1016/0022-4405(75)90006-0 
Stroebe, K., Lodewijkx, H. F. M., \& Spears, R. (2005). Do unto others as they do unto you: Reciprocity and social identification as determinants of ingroup favoritism. Personality and Social Psychology Bulletin, 31(6), 831-845. https://doi.org/10.1177/0146167204271659

Sutter, M., Zoller, C., \& Glätzle-Rützler, D. (2019). Economic behavior of children and adolescents - A first survey of experimental economics results. European Economic Review, 111, 98-121. https://doi.org/10.1016/j.euroecorev.2018.09.004

Tajfel, H., \& Turner, J. C. (1979). An integrative theory of intergroup conflict. In W. G. Austin \& S. Worchel (Eds.), The Social Psychology of Intergroup Relations (pp. 33-47). Brooks/Cole.

Tajfel, H., Billig, M. G., Bundy, R. P., \& Flament, C. (1971). Social categorization and intergroup behaviour. European Journal of Social Psychology, 1(2), 149-178. https://doi.org/10.1002/ejsp.2420010202

Tipton, E. (2015). Small sample adjustments for robust variance estimation with metaregression. Psychological Methods, 20(3), 375-393.

\section{https://doi.org/10.1037/met0000011}

Tipton, E., \& Pustejovsky, J. E. (2015). Small-sample adjustments for tests of moderators and model fit using robust variance estimation in meta-regression. Journal of Educational and Behavioral Statistics, 40(6), 604-634. https://doi.org/10.3102/1076998615606099

van Aert, R. C. M. (2021). puniform: Meta-analysis methods correcting for publication bias.

\section{https://cran.r-project.org/package=puniform}

van Aert, R. C. M., \& van Assen, M. A. L. M. (2020). Correcting for publication bias in a meta-analysis with the p-uniform* method. MetaArXiv. https://doi.org/10.31222/osf.io/zajr9

Van Lange, P. A. M., Manesi, Z., Meershoek, R. W. J., Yuan, M., Dong, M., \& Van Doesum, N. J. (2018). Do male and female soccer players differ in helping? A study on 
prosocial behavior among young players. PLOS ONE, 13(12), e0209168. https://doi.org/10.1371/journal.pone.0209168

Van Vugt, M., Cremer, D. D., \& Janssen, D. P. (2007). Gender differences in cooperation and competition. Psychological Science, 18(1), 19-23. https://doi.org/10.1111/j.1467$\underline{9280.2007 .01842 . x}$

Vevea, J. L., \& Hedges, L. V. (1995). A general linear model for estimating effect size in the presence of publication bias. Psychometrika, 60(3), 419-435.

\section{https://doi.org/10.1007/BF02294384}

Viechtbauer, W. (2010). Conducting meta-analyses in R with the metafor package. Journal of Statistical Software, 36(3), 1-48. http://www.jstatsoft.org/v36/i03/

Wentzel, K. R. (2013). School adjustment. In I. B. Weiner, Arthur M. Nezu, Christine M. Nezu, \& Pamela A. Geller (Eds.), Handbook of Psychology (pp. 213-232). Wiley.

West, S. A., Griffin, A. S., \& Gardner, A. (2007). Social semantics: Altruism, cooperation, mutualism, strong reciprocity and group selection. Journal of Evolutionary Biology, 20(2), 415-432. https://doi.org/10.1111/j.1420-9101.2006.01258.x

Yamagishi, T., \& Kiyonari, T. (2000). The group as the container of generalized reciprocity. Social Psychology Quarterly, 63(2), 116-132. https://doi.org/10.2307/2695887

Yamagishi, T., Jin, N., \& Kiyonari, T. (1999). Bounded generalized reciprocity: Ingroup boasting and ingroup favoritism. In E. J. Lawler (Series Ed.) \& S. R. Thye, E. J. Lawler, M. W. Macy, \& H. A. Walker (Vol. Eds.), Advances in Group Processes (pp. 161-197). Emerald.

*Yu, J., Zhu, L., \& Leslie, A. M. (2016). Children's sharing behavior in mini-dictator games: The role of in-group favoritism and theory of mind. Child Development, 87(6), 17471757. https://doi.org/10.1111/cdev.12635 